\title{
Importancia de la educación en derechos humanos para estudiantes de básica secundaria
}

\section{Importance of human rights education for basic secondary students}

\author{
1 \\ José Alberto Contreras Mancera ${ }^{2}$ \\ José Eriberto Cifuentes Medina ${ }^{3}$ \\ Universidad Pedagógica y Tecnológica de \\ Colombia
}

\section{RESUMEN}

El presente artículo pretende hacer un esbozo de la necesidad y el valeroso conocimiento y formación que los estudiantes de Educación Básica Secundaria han de consolidar con relación a los Derechos Humanos. Se realiza una revisión sistemática de la literatura, afin al objeto de estudio, valorando la fundamentación teórica que prevalece pero también la tarea de valentía por parte de los profesores que de seguro es 1 Artículo de Reflexión. Hace parte del trabajo de grado de la Maestría en Derechos Humanos y que se titula Recursos didácticos para la enseñanza de los Derechos Humanos en básica secundaria Institución Educativa El Cusiana municipio de Tauramena Casanare.

$2 \quad$ Magister (C) en Derechos Humanos, Universidad Pedagógica y Tecnológica de Colombia UPTC. Licenciado en Educación Básica con Énfasis en Ciencias Sociales, Universidad de Pamplona. Docente Secretaría de Educación de Casanare. Correo electrónico: jacom1573@hotmail.com https://orcid.org/0000-0003-4097-3248

3 Investigador Asociado (I) MinCiencias. Magister en Educación, Especialista en Evaluación Educativa, Especialista en Pedagogía y Docencia, Licenciado en Teología, Licenciado en Filosofía y Educación Religiosa, Universidad Santo Tomás. Docente Universidad Pedagógica y Tecnológica de Colombia. Orcid ID: https://orcid.org/0000-0001-5702620X. Correo electrónico: joseeriberto.cifuentes@uptc.edu. $\underline{\mathrm{CO}}$ necesario pueda lograr que trascienda las aulas de clase y que junto con sus estudiantes pueda fortalecer las bases de una formación humana y en derechos humanos sólida, que como sol logre cada estudiante ser luz para su familia, comunidad y sociedad. Se ha de fortalecer la Educación en Derechos Humanos para que cada estudiante pueda superar el analfabetismo y ser consecuente como ser humano.

Es necesario y consecuente el estudio riguroso de la literatura que en todas sus dimensiones existe acerca de los Derechos Humanos para la fundamentación teórica y conceptual pero también para el cultivo de humanidad y de conciencia acerca del conocimiento y de aplicación in situ de todos y cada uno de los Derechos Humanos, base para una sociedad humana fraterna sin distinción alguna de raza, color, credo religioso, ideología o cualquier particularidad; sobre la base de que cada individuo humano logre ser teniendo en cuenta con respeto y dignidad. De este modo el 
escenario educativo constituye una posibilidad para conocer y fortalecer las bases de teoría y praxis de los Derechos Humanos en razón de transformar una sociedad que así lo requiere, y que cada estudiante se impacte con su presencia en la familia y la sociedad como un ser más humano entre los humanos y un labrador de paz y de vida.

PALABRAS CLAVE: Derechos Humanos, Estudiantes, Básica Secundaria, Educación en Derechos Humanos, DBA

\section{ABSTRAC:}

This article aims to make an outline of the need and the courageous knowledge and training that students of Basic Secondary Education have to consolidate in relation to Human Rights. A systematic review of the literature is carried out, in order to the object of study, assessing the prevailing theoretical foundation but also the task of courage on the part of the teachers that surely it is necessary to achieve that it transcends the classrooms and that together with his students he can strengthen the foundations of a solid human formation and human rights; May each student be a light for her family, community and society like the sun. Human Rights Education must be strengthened so that each student can overcome illiteracy and be consistent as a human being.

The rigorous study of the literature that exists in all its dimensions about Human Rights is necessary and consequent for the theoretical and conceptual foundation but also for the cultivation of humanity and consciousness about the knowledge and application in situ of each and every one of Human Rights, the basis for a fraternal human society that without any distinction of race, color, religious creed, ideology or any particularity; each human individual achieves to be considered with respect and dignity. Being the educational scenario a possibility to know and strengthen the bases of theory and practice of Human Rights to transform in a unity a society that requires it, from each student they are impacted with their presence in the family and society as one more being human among humans and a farmer of peace and life.

KEYWORDS: Human Rights, Students, Basic Secondary, Human Rights Education, DBA

\section{INTRODUCCIÓN}

La formación en Derechos Humanos precisa tener claro qué son los Derechos Humanos. Llegar a un consenso en su definición no es tarea fácil puesto que hay diferencias entre los principales autores. Al respecto la Organización de las Naciones Unidas ONU (s. f.) tiene un punto de vista filosófico iusnaturalista y define los Derechos Humanos como atributos que tiene el ser humano por el simple hecho de ser humano, es decir son inherentes a las personas y como inherentes son inalienables, indivisibles y de carácter universal, porque todas las personas tienen los mismos derechos sin importar su raza, genero u origen. Sin embargo, parafraseando a Pérez Luño (1999) se puede decir que los Derechos Humanos son el conjunto de facultades que han ganado las personas a través de la historia mediante las exigencias de libertades, igualdad entre las personas y dignidad; estos derechos son un constructo social y necesitan positivización, es decir ser reconocidos jurídicamente por los organismos nacionales e internacionales. En ese sentido la Declaración Universal de los Derechos Humanos DUDH forma parte de esa positivización en la medida que es aceptada por los diferentes estados.

\section{DESARROLLO}

Los Derechos Humanos son las conquistas y los mecanismos de protección de los ciudadanos, plasmados en los textos constitucionales y legales. De su observancia y aplicación real depende la existencia jurídica, política y económica de una sociedad democrática. 
También podrían definirse como los beneficios o libertades públicas fundamentales establecidas por la Constitución y las leyes, de las que goza el ciudadano y la persona. Una característica de los sistemas de gobierno democrático, es que se preocuparon por enunciar cuidadosamente los derechos de sus asociados, según la Constitución de 1991, que actualmente nos rige presenta la clasificación y organización de los Derechos Humanos.Tabla $N^{\circ}$ 1: Los Derechos de los colombianos

\begin{tabular}{|c|c|c|}
\hline DERECHOS & DEFINICIÓN & EJEMPLOS \\
\hline Fundamentales & $\begin{array}{l}\text { Son aquellas condiciones de las } \\
\text { que debemos gozar por el hecho de } \\
\text { ser seres humanos. Los derechos } \\
\text { fundamentales nos pertenecen } \\
\text { a todos, independientemente de } \\
\text { nuestra raza, credo, posición, política, } \\
\text { sexo, clase social, etc. }\end{array}$ & $\begin{array}{l}\text { El derecho a conservar la vida en } \\
\text { condiciones dignas y con posibilidad } \\
\text { permanente de desarrollo } \\
\text { El derecho a pensar diferente, de no } \\
\text { estar de acuerdo, de expresar ideas } \\
\text { y de unirnos a otras personas para } \\
\text { alcanzar metas comunes } \\
\text { El derecho a ser tratados en igualdad } \\
\text { de condiciones, sin importar el sexo, } \\
\text { el color de la piel, el credo o la filiación } \\
\text { política }\end{array}$ \\
\hline $\begin{array}{l}\text { Sociales, } \\
\text { económicos y } \\
\text { culturales }\end{array}$ & $\begin{array}{l}\text { Son aquellos que se aplican a grupos } \\
\text { concretos, tales como la familia, los } \\
\text { niños, los ancianos, los trabajadores, } \\
\text { etc. }\end{array}$ & $\begin{array}{l}\text { Los derechos de la familia, los } \\
\text { derechos especiales para los niños, } \\
\text { los jóvenes, los ancianos, las mujeres } \\
\text { y lo minusválidos. } \\
\text { El derecho a la seguridad social, a } \\
\text { los servicios de salud, a una vivienda } \\
\text { digna, a la recreación y el deporte, al } \\
\text { trabajo, a la educación y a la cultura. }\end{array}$ \\
\hline $\begin{array}{l}\text { Colectivos y del } \\
\text { ambiente }\end{array}$ & $\begin{array}{l}\text { Los derechos colectivos con los que } \\
\text { nos pertenecen como miembros de } \\
\text { una comunidad }\end{array}$ & $\begin{array}{l}\text { Los derechos al espacio público } \\
\text { (parques, calles y vías de transporte) } \\
\text { El derecho a la buena calidad de } \\
\text { los alimentos y de otros bienes y } \\
\text { servicios prestados a la comunidad } \\
\text { El derecho a gozar de una ambiente } \\
\text { sano y al adecuado manejo de los } \\
\text { recursos naturales }\end{array}$ \\
\hline
\end{tabular}

Fuente: Información recaba de manuales de Historia 
Los Derechos de la Personas, son derechos y garantías que otorga la Constitución de Colombia de 1991, en otros se constatan los siguientes:

"El derecho a la vida, a la libertad, al trabajo en condiciones justas y dignas, al reconocimiento de su personalidad jurídica, al libre desarrollo de su personalidad, a la intimidad personal y familiar y al buen nombre, a conocer, actualizar y rectificar las informaciones que se hayan recogido de ellas en bancos de datos y en entidades públicas y privadas, a la libertad de escoger profesión u oficio, garantizará la libertad de conciencia, a la libertad de culto, a la libertad de pensamiento, opinión y expresión, a la honra, a la libre asociación (Constitución de 1991).

Por lo tanto, la formación humana de cada individuo acerca de la condición humana y de sus derechos e inherente al paso por la educación básica y fundamental para toda a vida, por cuanto su interacción con los demás seres humanos es permanente y siempre ha de estar demarcada por el respeto de la dignidad individual y colectiva.

\section{CLASIFICACIÓN DE LOS DERECHOS HUMANOS}

El reconocimiento legal de los Derechos Humanos ha tenido una larga historia. Algunos derechos han sido incluidos en las leyes mucho antes que otros, que sólo han sido aceptados después de largas luchas sociales, tales derechos forman parte del constructo social y se han obtenido en las calles, han dejado mártires a su paso, saben a sangre, a sudor y lágrimas. Por lo tanto, se pueden clasificar los derechos en grupos, a los que se les denomina generaciones de los Derechos Humanos.

\section{TRES GENERACIONES DE DERECHOS HUMANOS.}

La división de los Derechos Humanos en tres generaciones fue realizada por primera vez por Karel Vasak en 1979. Cada una se asocia a uno de los grandes valores proclamados en la Revolución Francesa: libertad, igualdad, solidaridad.

Tabla $N^{\circ} 2$ Las tres generaciones de los derechos humanos

\begin{tabular}{|c|c|c|c|l|l|}
\hline $\begin{array}{c}\text { Generación de } \\
\text { Derechos }\end{array}$ & $\begin{array}{c}\text { Época } \\
\text { De } \\
\text { aceptación }\end{array}$ & $\begin{array}{c}\text { Tipo de } \\
\text { derechos }\end{array}$ & $\begin{array}{l}\text { Valor que } \\
\text { defienden }\end{array}$ & Función principal & \multicolumn{1}{|c|}{ Ejemplos } \\
\hline Primera & $\begin{array}{c}\text { Siglos } \\
\text { XVIII y XIX }\end{array}$ & $\begin{array}{l}\text { Civiles y } \\
\text { políticos }\end{array}$ & Libertad & $\begin{array}{l}\text { Limitar la acción } \\
\text { del poder. } \\
\text { Garantizar la } \\
\text { participación } \\
\text { política de los } \\
\text { ciudadanos. }\end{array}$ & $\begin{array}{l}\text { Derechos Civiles: } \\
\text { Derecho a la vida, } \\
\text { a la Libertad, a } \\
\text { la seguridad a } \\
\text { la propiedad... } \\
\text { Derechos } \\
\text { Políticos: Derecho } \\
\text { al voto, a la } \\
\text { asociación, a la } \\
\text { huelga... }\end{array}$ \\
\hline
\end{tabular}




\begin{tabular}{|c|c|c|l|l|l|}
\hline Segunda & $\begin{array}{c}\text { Siglos } \\
\text { XIX y XX }\end{array}$ & $\begin{array}{c}\text { Económicos, } \\
\text { Sociales y } \\
\text { Culturales }\end{array}$ & Igualdad & $\begin{array}{l}\text { G a r a } \mathrm{n} \mathrm{t} \mathrm{i} \mathrm{z} \mathrm{a} \mathrm{r} \\
\text { condiciones de } \\
\text { vida dignas para } \\
\text { todos }\end{array}$ & $\begin{array}{l}\text { Derechoala salud, } \\
\text { a la educación, } \\
\text { al trabajo, a una } \\
\text { vivienda digna... }\end{array}$ \\
\hline Tercera & $\begin{array}{c}\text { Siglos } \\
\text { XX y XXI }\end{array}$ & $\begin{array}{c}\text { Justicia, paz y } \\
\text { solidaridad }\end{array}$ & Solidaridad & $\begin{array}{l}\text { Promover } \\
\text { relaciones } \\
\text { pacíficas y } \\
\text { constructivas }\end{array}$ & $\begin{array}{l}\text { Derecho a un } \\
\text { medio ambiente } \\
\text { limpio, a la paz, al } \\
\text { desarrollo... }\end{array}$ \\
\hline
\end{tabular}

Fuente: Tomado y adaptado de http://recursostic.educacion.es/

La división de los Derechos Humanos en tres generaciones una posible forma de clasificación que no demarca el nivel de importancia porque todos requieren el mismo valor consecuente de Derecho, por tanto, han de ser respetados porque tienen el mismo grado de importancia y aplicabilidad para todos los seres humanos.

\section{¿POR QUÉ EDUCAR EN DERECHOS HUMANOS?}

La educación ha de ser vista con detenimiento debe ser fundamental en todos los seres humanos, no en vano los gobiernos alrededor del mundo vienen concentrando esfuerzos para mejorar su calidad en cada uno de sus territorios, desde la concepción de la DUDH, se estima el derecho a la educación como uno de sus baluartes y si bien es cierto ningún derecho es más importante que otro, hay derechos clave para poder disfrutar de los demás derechos, en este grupo se puede destacar el derecho a la vida, sin este no podríamos disfrutar de algún otro derecho, el derecho a la salud y por supuesto el derecho a la educación, si bien es cierto una persona sin educación puede vivir, eso no le garantiza que tenga igualdad de oportunidades frente a los demás por ejemplo en el sistema laboral y por ende un salario digno, recreación y todo lo que esto conlleva.

La DUHD (ONU 1948) en su preámbulo establece la promoción de los Derechos Humanos mediante la enseñanza, la educación y el respeto por los mismos, originando así la Educación en Derechos Humanos EDH, destacando que es necesario que todas las personas conozcan sus derechos y puedan hacer usos de ellos, la búsqueda de igualdad entre las personas y que todo el mundo tenga las mismas oportunidades es uno de los pilares de la declaración y que mejor forma de lograrlo que dotar al individuo de las herramientas necesarias, para fortalecer esta idea la misma DUDH Artículo 26, inciso 2, proclama;

La educación tendrá por objeto el pleno desarrollo de la personalidad humana y el fortalecimiento del respeto a los derechos humanos y a las libertades fundamentales; favorecerá la comprensión, la tolerancia y la amistad entre todas las naciones $y$ todos los grupos étnicos o religiosos, y promoverá el desarrollo de las actividades de las Naciones Unidas para el mantenimiento de la paz. (DUDH, 1948, Art. 26)

La Educación en Derechos Humanos - EDH, según Magendzo (2005) es la; "practica educativa que se funda en el reconocimiento, la defensa, el respeto, y la promoción de los derechos humanos y que tiene por objeto desarrollar en los individuos y los pueblos, sus máximas capacidades como sujetos de derechos" (p. 31) de esta forma obteniendo lo necesario para hacer que dichos derechos sean efectivos. Por su parte Rodino (2003) afirma que 
la educación en Derechos Humanos "enseña la importancia de conocer, valorar y respetar los derechos de las personas como exigencia de su condición de seres humanos y como pautas de convivencia social inclusiva, justa, pacífica y solidaria" (p. 10). Teniendo en cuenta a Magendzo (2005) como a Rodino (2017), se puede decir que una sociedad donde hay EDH hay justicia, libertad, paz, solidaridad, tolerancia y sobre todo respeto hacia los demás, logrando de esta forma mejorar la convivencia y por ende brindando dignidad a las personas.

Hay que mencionar, además que no es solo se trata de educar en Derechos Humanos, sino también educar para los Derechos Humanos, según Rodino (2017) la EDH ha de "ser el vehículo para que todas las personas, conozcan, ejerzan y defiendan tanto sus propios derechos como los derechos de los demás, convirtiendo a la EDH en una práctica mediadora que transforma la sociedad" (p. 38), es decir la EDH es el puente que se debe transitar de manera obligatoria para pasar de la consagración de los derechos en las normas a su efectiva aplicación en la realidad. por dos razones, i toda norma debe ser difundida antes de llevarse a la práctica a través de una actividad educativa que permita que los agentes sociales conozcan y multipliquen los derechos y ii ningún derecho puede ser puesto en práctica si no es multiplicado a todas las personas a través de actividades o multiplicadores educativos, educar en derechos es brindar a la personas las herramientas necesarias para que actúen como sujetos de derechos y a sus vez para que repliquen esos derechos en su quehacer cotidiano.

La EDH entendida como el conjunto de acciones y actividades de carácter educativo encaminadas a desarrollar habilidades que promuevan el respeto por los Derechos Humanos, la convivencia social y el bienestar común, tiene la responsabilidad de concebir personas capaces de generar un cambio en la sociedad, en el que se destaque la igualdad, equidad, y sobre todo el respeto por la dignidad humana.

\section{OBJETIVOS DE LA EDUCACIÓN EN DERECHOS HUMANOS}

En cuanto a los objetivos de la EDH se puede destacar como principal la defensa efectiva de los derechos humanos, para ello es necesario recurrir a un segundo objetivo que, parafraseando a Magendzo (2005) corresponde a la formación de personas como sujetos de derechos, haciendo énfasis en que un sujeto de derechos tiene las herramientas básicas para promover, ejercer y defender los derechos tanto propios como los de sus semejantes, de estas herramienta el autor resalta el conocimiento de los cuerpos normativos que se refieren a los derechos fundamentales de las personas como la Declaración Universal de los Derechos Humanos DUDH, resoluciones, acuerdos, convenciones, declaraciones y tratados internacionales, además conoce las instituciones que tienen como función la promoción y defensa de los Derechos Humanos, también posee competencias lingüísticas, es capaz de actuar sobre el mundo defendiendo y exigiendo que se cumplan tanto sus derechos como los de su comunidad, siendo una persona vigilante de sus semejantes.

Por su parte Rodino (2017) afirma que el objetivo de la EDH no es solo la transmisión de información y conceptos acerca de los derechos, sino que esta busca formar a las personas para que se conciban y actúen como sujetos de derechos, formar en una visión para prácticas de vida coherentes con los valores de los derechos humanos, de esta forma creando una cultura de Derechos Humanos, a su vez que establece tres fines de la educación; i fines éticos, ii fines críticos, iii fines políticos, además considera que educar en derechos es educar en democracia y formación para el ejercicio de la ciudadanía, propone que los Derechos Humanos como pautas que regulen la convivencia social, de ahí 
que se entiendan los derechos no solo como responsabilidad de los organismos del estado y por el contrario se debe entender y asumir como una responsabilidad de todas las personas, debido a que de ello depende la felicidad como individuos, la sostenibilidad como sociedades democráticas y la supervivencia como especie.

Se trata de lograr que los derechos humanos se internalicen y lleguen a formar parte de los modos de vida y costumbres compartidos y valorados que constituyen la definición de cultura; de esa argamasa que une a los miembros de una comunidad por encima de sus muchas y legítimas diferencias. Hablamos aquí de una comunidad enorme, la más grande concebible $\mathrm{y}$, al mismo tiempo, la más básica: la especie humana. para como un fin mismo de dicha declaración siendo a la vez uno mismo de sus derechos establecidos (Rodino, 2016, p. 24)

Los dos autores concuerdan que el objetivo principal de la EDH es la formación de ciudadanos como sujetos de derechos, autónomos y críticos, capaces de promover, ejercer, respetar y sobretodo defender y hacer cumplir sus derechos y los de los demás, causando un cambio en la convivencia social $y$ de una $u$ otra forma mejorando la calidad de vida de las personas. Dicho lo anterior, cabe resaltar que tanto el derecho a la educación como la EDH son herramientas que garantizan el disfrute de los demás derechos, además la EDH en sí misma es otro Derecho Humano y se considera un derecho llave porque abre las posibilidades a otros derechos.

\section{REFERENTES SOBRE EDUCACIÓN EN DERECHOS HUMANOS EN COLOMBIA.}

El ejercicio de los Derechos Humanos en Colombia no ha sido algo fácil en los últimos años, evidencia de ello es el aumento de homicidios selectivos y masacres a líderes sociales y la población civil en general, según INDEPAZ (2020) a octubre de 2020 se han perpetrado 66 masacres, dejando un saldo de 233 líderes y defensores de los Derechos Humanos y 82 indígenas muertos de manera violencia a lo largo y ancho del país, es la razón principal porque la que urge que la EDH en Colombia logre un tan anhelado cambio para nuestra sociedad y logre crear esa cultura de Derechos Humanos de la que refiere Rodino (2016).

Acerca de esta situación Luis Pérez (s. f.) citado en Russi (2011) habla del analfabetismo en Derechos Humanos y es vigente su postulado puesto que el pan de cada día sigue siendo la discriminación, xenofobia, aporofobia, masacres, violencia de género entre otros y además es un problema que parece empeorar con el paso del tiempo, aduciendo que no estamos educados bajo una cultura de derechos y que los mismos no se respetan y mucho menos hacen parte de nuestra vida cotidiana es por eso que la educación debe pensarse de tal forma que se convierta en el vehículo transformador capaz de convertir a los ciudadanos en sujetos de derechos y contribuya a mejorar la convivencia social Rodino (2016).

Con respecto a lo que se viene haciendo en materia de EDH en Colombia, se debe resaltar que al aceptar la DUDH donde ya se mencionó es el primer documento promotor de la EDH, el país adquiere un compromiso que luego va reflejando en su legislación y programas de gobierno que de una $u$ otra forma brindan orientaciones y parámetros para la puesta en marcha de estrategias para la EDH, en concordancia con esto se refleja que el primer paso se da en la constitución política de 1991 con la inclusión de los derechos fundamentales, los derechos económicos, sociales y culturales, pero primordialmente con el artículo $67 \mathrm{del}$ documento el cual establece: 
Artículo 67. La educación es un derecho de la persona y un servicio público que tiene una función social (...) La educación formará al colombiano en el respeto a los derechos humanos, a la paz y a la democracia; y en la práctica del trabajo y la recreación, para el mejoramiento cultural, científico, tecnológico y para la protección del ambiente. (Constitución política de Colombia, 1991)

En el artículo mencionado se puede evidenciar que tiene un carácter vinculante en el entendido que compromete al estado a respetar este derecho y lo compromete a que se garantice el pleno ejercicio del mismo y además lo condiciona a cumplir ciertos parámetros en el que se puede destacar que se deben respetar los Derechos Humanos, a su vez determina que la educación además de un derecho, es un servicio público y un deber tanto del ciudadano como del estado, pero como mencionábamos anteriormente para respetarlos es necesario promoverlos y eso solo se logra a través de la Educación en Derechos Humanos.

Por su parte en medio de la reforma educativa de la mitad de la década de los 90 , el congreso de la república promulga la ley general de educación o ley 115 de 1994 que establece.

Artículo 14. Enseñanza obligatoria. En todos los establecimientos oficiales - privados que ofrezcan educación formal es obligatorio en los niveles de la educación preescolar, básica y media, cumplir con; (...) Literal d) La educación para la justicia, la paz, la democracia, la solidaridad, la confraternidad, el cooperativismo y, en general, la formación en los valores humanos,... (Ley 115 de 1994)

La ley 115 de 1994, exige a las instituciones educativas, secretarías de educación y Ministerio de Educación Nacional MEN, el compromiso con la EDH, para el efectivo ejercicio de los demás componentes mencionados y en búsqueda de la cultura de Derechos Humanos. Siendo el hogar la primera escuela, la ley también establece obligaciones a los padres para la formación de la personalidad del niño encaminadas a formar ciudadanos comprometidos con la mejora de la convivencia social.

En este sentido el máximo referente por parte del estado colombiano en materia de EDH es el Plan Nacional de Educación en Derechos Humanos - PLANEDH, adoptado por el gobierno nacional, con la participación la vicepresidencia de la república, el Ministerio de Educación Nacional y la defensoría del pueblo, dando cumplimiento a recomendaciones dadas por las Naciones Unidas, y ratificando los compromisos adquiridos al reconocer dichos protocolos en los cuales se puede destacar por su mayor grado de relevancia en cuento al tema los siguientes; Convención sobre los Derechos del Niño, Pacto Internacional de Derechos Económicos, Sociales y Culturales, Protocolo de San Salvador, adicional a la Convención Americana sobre derechos humanos, en materia de Derechos Económicos, Sociales y Culturales, La declaración sobre el derecho y el deber de promover y proteger los Derechos Humanos.

Si bien es cierto el PLANEDH se convierte en la hoja de ruta, deja en evidencia la falta de preparación del estado colombiano en cuanto a EDH se refiere, toda vez que no cuenta con herramientas suficientes ni mucha legislación al respecto, adicional a eso se debe tener en cuenta que a pesar de que es obligación educar en y para los Derechos Humanos, la gran dificultad es que no hay orientaciones claras de quien lo debe asumir y se evidencia en las instituciones educativas que por lo regular en su PEI establecen la EDH como un proyecto transversal que al final termina siendo una actividad de papel que por problemas de tiempo y recursos casi nunca se puede 
realizar y termina no cumpliendo su objetivo que es formar sujetos de derechos, de ahí que seguimos recibiendo informes negativos como por ejemplo la cantidad de masacres en el año, o los feminicidios cometidos, o el aumento de violencia intrafamiliar en tiempos de pandemia, es por eso que ha se convertido en algo normal que los políticos tomen los recursos de la nación como propios y no se diga nada y además como para completar el país está polarizado entre los pertenecientes a un bando político y sus contradictores que todo el tiempo están peleando entre ellos sin tener en cuenta que están en igualdad de condiciones.

Entre los años 2006 a 2009 bajo la premisa de la formación para el ejercicio de los Derechos Humanos, se lleva a cabo el programa piloto Eduderechos donde se focalizaron 77 establecimientos educativos de 7 secretarías de educación de diferentes entidades territoriales del país, siendo Bolívar, Boyacá, Caquetá, Córdoba, Huila, Guaviare y Norte de Santander los departamentos escogidos porque cada uno en su momento tenían condiciones especiales de convivencia social, con altos índices de violencia intrafamiliar, desplazamiento forzado, cultivos ilícitos entre otros, en este caso se personalizaron rutas metodológicas de acuerdo el contexto socio cultural de cada establecimiento, siendo uno de los primeros pasos en EDH por parte del MEN, se hizo acompañamiento a docentes, estudiantes $y$ padres de familia, este programa no sugiere área del conocimiento específica donde se deba orientar en formación de la ciudadanía y deja autonomía a las instituciones, en la mayoría de los casos la transversalidad es la opción más aceptada.

Así, la educación para el ejercicio de los derechos humanos es un llamado para hacer de la escuela un espacio de vivencia cotidiana de la democracia y la convivencia pacífica, en la que no existe la discriminación y se reconoce la dignidad humana como un valor supremo, en la que se crean ambientes de aprendizaje democráticos y se promueven la libertad de información y expresión, una escuela que considera a las personas como fin y no como medio, para que los derechos humanos sean una realidad en todos los contextos de la vida. (MEN s. f.)

En Colombia no existe una catedra especial que determine la $\mathrm{EDH}$, se ha puesto como tarea para las competencias ciudadanas prueba de ello se puede apreciar en los programas planteados desde el Ministerio de Educación Nacional MEN, en 2011 con la creación del programa Brújula se busca fomentar las competencias ciudadanas, convirtiéndose en la guía que servirá para orientar a la comunidad educativa de tal forma que niños, niñas y jóvenes puedan ser formados como ciudadanos activos en ejercicios de sus derechos.

Si bien el impacto que se espera al desarrollar competencias ciudadanas en el aula tiene que ver con el currículo oculto, dentro de las áreas académicas definidas por la Ley General de Educación (Art. 23, Congreso de la República, 1994) existen dos cuyos contenidos se relacionan íntimamente con los conocimientos necesarios para el desarrollo de competencias ciudadanas, a saber, Constitución y Democracia y Ética y Valores humanos. (MEN 2011)

La firma del acuerdo de paz marca un hito en la historia de Colombia, se pone fin a un conflicto que tiene más de 50 años entre los agentes del estado y la guerrilla de las FARC, el perdón, la reconciliación, la justicia y la no repetición, han de ser términos que maneje y aplique a la perfección la sociedad nacional, pero así como los Derechos Humanos han sido constructos sociales, se debe seguir trabajando en ello, es por eso que producto del acuerdo se ve la 
necesidad de preparar a los ciudadanos para que el punto de no repetición se cumpla y para ello a través de la Ley 1732 de 2014 se establece que en adelante todas las instituciones educativas de carácter público o privado en los niveles de preescolar, básica y media, deberán implementar de manera obligatoria la catedra de paz con el fin de desarrollar habilidades para la convivencia social, respeto por el medio ambiente, desarrollo sostenible y cultura de paz, entendida "como la apropiación de conocimientos y competencias ciudadanas para la convivencia pacífica, la participación democrática, la construcción de equidad, el respeto por la pluralidad, los Derechos Humanos y el Derecho Internacional Humanitario". (Decreto 1038 de 2015) de igual forma el decreto regulador a pesar de que da autonomía a las I. E para la implementación, sugiere que esta sea aplicada en las áreas de Ciencias Sociales, Historia, Geografía, Constitución Política y Democracia; Ciencias Naturales y Educación Ambiental, o Educación Ética y en Valores Humanos.

Conviene subrayar los esfuerzos que se vienen adelantando tras el acuerdo para la paz, se ha evidenciado la necesidad de resolver inquietudes y hacer reajustes en los contenidos educativos, es por eso que desde el Ministerio de Educación Nacional MEN se brindan los Lineamientos de Formación de Educadores para la Ciudadanía Proyecto "Desarrollo e integración curricular de la Educación para la Ciudadanía Mundial - ECM" (MEN 2018) dirigido especialmente a instituciones de educación superior y escuelas normales superiores del país, ya que son estas las encargadas de la formación de los trabajadores de la educación, con el cual se busca formar docentes que tengan las herramientas necesarias que en el ejercicio de su labor repliquen en sus estudiantes una educación para el ejercicio de la ciudadanía, teniendo en cuenta un enfoque de Derechos Humanos, igualdad de género, convivencia pacífica, inclusión social y justicia, coincidiendo con la agenda 2030 el objetivo de desarrollo sostenible $\mathrm{N}^{\circ} 4$ que propone una educación de calidad, equitativa e inclusiva y que a su vez tiene como metas entre otras, eliminar la discriminación y formar para una ciudadanía global.

\section{REFERENTES DE EDUCACIÓN EN DERECHOS HUMANOS EN COLOMBIA.}

El año 2015 está caracterizado por ser un año que contempla grandes cambios en la estructura de contenidos educativos para los niveles de preescolar, básica y media, la socialización y puesta en marcha de los Derechos Básicos de Aprendizaje DBA en sus primeras versiones en las áreas de Matemáticas, Lenguaje y Ciencias Naturales marcan este hito, en 2016 se hacen ligeros cambios a los DBA presentados el año anterior y aparecen en su primera versión los correspondientes al área de Ciencias Sociales, estos se caracterizan porque sus contenidos están ajustados en concordancia con la firma del acuerdo de paz de La Habana, la ley 1732 de 2014 y el decreto 1038 de 2015, si bien es cierto estos referentes no dejan toda la responsabilidad al área para asumir la catedra de paz, se puede decir que hay de dónde empezar a partir de los DBA. Para efectos de básica secundaria, objeto de estudio hay DBA directamente relacionados con la defensa de los Derechos Humanos, democracia, cultura de paz, pilares esenciales en la construcción de sociedad. A continuación, se presentará un análisis de los DBA de Ciencias Sociales que más se relacionan con los ítems mencionados por grado en Básica Secundaria. 
Tabla $N^{\circ}$ 3. Análisis de DBA referentes de Derechos Humanos

\begin{tabular}{|c|c|c|}
\hline Grado & Derecho Básico de Aprendizaje & Análisis \\
\hline Sexto & $\begin{array}{l}\text { DBA 8: Comprende que en una sociedad } \\
\text { democrática no es aceptable ninguna } \\
\text { forma de discriminación por origen étnico, } \\
\text { creencias religiosas, género, discapacidad } \\
\text { y/o apariencia física. }\end{array}$ & $\begin{array}{l}\text { Relacionado directamente } \\
\text { con los artículos } 2 \text { y } 7 \text { de la } \\
\text { DUDH, en concordancia con la } \\
\text { constitución de } 1991 \text { pretende } \\
\text { que se brinden herramientas con } \\
\text { el fin de eliminar todas las formas } \\
\text { de discriminación en la sociedad. } \\
\text { Destacando la igualdad como } \\
\text { derecho y principio fundamental }\end{array}$ \\
\hline Séptimo & $\begin{array}{l}\text { DBA 7: Comprende la responsabilidad que } \\
\text { tiene una sociedad democrática para evitar } \\
\text { la violación de los derechos fundamentales } \\
\text { de sus ciudadanos. }\end{array}$ & $\begin{array}{l}\text { Este DBA pretende brindar } \\
\text { herramientas que permitan } \\
\text { resaltar la importancia de la } \\
\text { democracia para la protección } \\
\text { efectiva de los derechos } \\
\text { fundamentales toda vez que se } \\
\text { debe buscar diferentes recursos } \\
\text { para la promoción de los mismos. } \\
\text { Confróntese con el capítulo } 1 \text {, } \\
\text { título II, constitución política de } \\
\text { Colombia 1991) }\end{array}$ \\
\hline Séptimo & $\begin{array}{l}\text { DBA 8: Aplica procesos y técnicas } \\
\text { de mediación de conflictos en pro del } \\
\text { establecimiento de una cultura de la paz. }\end{array}$ & $\begin{array}{l}\text { Resalta la importancia de } \\
\text { la solución de conflicto de } \\
\text { forma pacífica, pretende que } \\
\text { el estudiante logre evitar la } \\
\text { presencia de conflictos en el aula } \\
\text { y comunidad en general o en su } \\
\text { defecto obtenga herramientas } \\
\text { que permitan contrarrestar } \\
\text { la violencia sin generar más } \\
\text { violencia } \\
\text { Confróntese con el Artículo } 22 \text { de } \\
\text { constitución política de Colombia } \\
\text { 1991, } 1732 \text { de } 2014 \text { y Decreto } \\
\text { 1038 de } 2015\end{array}$ \\
\hline
\end{tabular}




\begin{tabular}{|c|c|c|}
\hline \multicolumn{3}{|c|}{$\begin{array}{l}\text { Análisis de los Derechos Básicos de Aprendizaje relacionados con Derechos Humanos en el área } \\
\text { de Ciencias Sociales en Básica secundaria }\end{array}$} \\
\hline Grado & Derecho Básico de Aprendizaje & Análisis \\
\hline Octavo & $\begin{array}{l}\text { DBA 7: Evalúa hechos trascendentales } \\
\text { para la dignidad humana (abolición de la } \\
\text { esclavitud, reconocimiento de los derechos } \\
\text { de las mujeres, derechos de las minorías) } \\
\text { y describe las discriminaciones que aún se } \\
\text { presentan. }\end{array}$ & $\begin{array}{l}\text { Da cuenta de la importancia que } \\
\text { tiene para la convivencia social } \\
\text { la eliminación de todo tipo de } \\
\text { discriminación y sometimiento, } \\
\text { brindando al estudiante } \\
\text { herramientas para la promoción } \\
\text { de los Derechos Humanos y } \\
\text { pautas para la identificación de } \\
\text { violaciones a los mismos en la } \\
\text { actualidad. } \\
\text { Confróntese con la DUDH }\end{array}$ \\
\hline Octavo & $\begin{array}{l}\text { DBA 8: Comprende la importancia de las } \\
\text { asociaciones, los gremios, los movimientos } \\
\text { y organizaciones sindicales en la defensa } \\
\text { de los derechos colectivos. }\end{array}$ & $\begin{array}{l}\text { Pretende resaltar la importancia } \\
\text { de los movimientos sociales en } \\
\text { la construcción de la democracia } \\
\text { y los Derechos Humanos y } \\
\text { a su vez brindar I estudiante } \\
\text { habilidades para la convivencia } \\
\text { y respeto hacia quienes piensan } \\
\text { diferente a ellos. } \\
\text { Confróntese con el capítulo 1, } \\
\text { título II, constitución política de } \\
\text { Colombia 1991) }\end{array}$ \\
\hline Noveno & $\begin{array}{l}\text { DBA 5: Evalúa cómo las sociedades } \\
\text { democráticas en un Estado social de } \\
\text { Derecho tienen el deber de proteger y } \\
\text { promover los derechos fundamentales de } \\
\text { los ciudadanos. }\end{array}$ & $\begin{array}{l}\text { Pretende resaltar la democracia } \\
\text { como mecanismo dinamizador } \\
\text { en el respeto y protección efectiva } \\
\text { de los derechos fundamentales, } \\
\text { fomentando la EDH como } \\
\text { herramienta de promoción de los } \\
\text { mismos. (Véase DBA 7, grado } \\
\text { 7) Confróntese con el capítulo } 1 \text {, } \\
\text { título II, constitución política de } \\
\text { Colombia } 1991\end{array}$ \\
\hline
\end{tabular}




\begin{tabular}{|c|l|l|}
\hline \multicolumn{2}{|c|}{ Análisis de los Derechos Básicos de Aprendizaje relacionados con Derechos Humanos en el área } \\
de Ciencias Sociales en Básica secundaria
\end{tabular}

Fuente: Elaboración propia a partir de los DBA ciencias Sociales Versión 1 (MEN 2016)

La revisión sistemática de los referentes para la Educación en Derechos Humanos en Colombia desde la Constitución Política de 1991, la Ley 115 de 1994 al igual que la ley 1732 de 2014 , el Decreto 1038 de 2015, lineamientos, estándares y se ha realizado un especial énfasis en los Derechos Básicos de Aprendizaje - DBA que la planteado en Ministerio de Educación Nacional de manera que desde el Área de Ciencias Sociales y sus cátedras adjuntas se logres visualizar la Educación en Derechos Humanos de los estudiantes de Básica Secundaría y consolide la formación ciudadana para fomentar un bienestar y mejorar las condiciones de la calidad de vida de cada ser humano.

\section{CONCLUSIONES}

La Educación en Derechos Humanos- EDH, ha de ser una realidad de la nueva escuela, que en efecto ha ganado terreno en el papel, pero a su vez se ha perdido en la práctica, lo que se puede evidenciar con solo prender el televisor $\mathrm{o}$ abrir una red social y ver las noticias nacionales, siendo la violencia en todas sus facetas el tema principal; el respeto por el otro se ha perdido, los valores de la sociedad han quedado en el olvido, hoy impera la ley del más fuerte. La Educación en los Derechos Humanos es responsabilidad de todos. Desde el mismo estado encontramos las fallas en el sistema, la corrupción quita recursos a la salud, infraestructura, servicios públicos, educación, generación de empleo, acceso a la 
vivienda y muchos más sectores y nadie parece hacer algo al respecto.

En Colombia se ha avanzado en materia de planeación de educación que ayude a fomentar una cultura de Derechos Humanos, pero no corresponde a la realidad nacional; a pesar de que la mujer ha sido reconocida como sujeto de derechos de especial protección se evidencia cada vez más la vulneración hacia esta población: los feminicidios, falta de oportunidades, discriminación por género son cada vez más frecuentes; la violencia de género no se ha erradicado y desde las redes sociales se ha satanizado la lucha frente a esta situación, polarizando políticamente al país y encajándolo en dos bandos donde el pensamiento neutral no tiene cabida y además es objeto de mayor discriminación.

Urge desarrollar políticas públicas en materia de educación en Derechos Humanos, donde se tenga en cuenta el contexto y necesidad de cada región y grupo poblacional, involucrando a todos los actores de la sociedad, brindando herramientas, recursos y capacitación al sector educativo y ampliando a otros sectores como la fuerza pública y entes de control, los medios de comunicación deben propender por promover una cultura de derechos que permita cambios significativos en la convivencia social.

\section{REFERENCIAS BIBLIOGRÁFICAS}

Congreso de Colombia. (8 de febrero de 1994) Artículo 14 [Título II]. Ley General de Educación. [Ley 115 de 1994]. Recuperado de: https:// www.mineducacion.gov.co/1759/ articles-85906_archivo_pdf.pdf

Constitución política de Colombia [Const.] (1991) Artículo 67 [Titulo II]. Recuperado de: https://www.ramajudicial.gov. co/documents/10228/1547471/ CONSTITUCION-Interiores.pdf
Derechos Humanos PBA (14 de diciembre de 2017) 8. Educación en y para los derechos Humanos - Ana María Rodino [archivo de video]. Recuperado de: https://www.youtube.com/ watch?v=vGFr1mSgwBQ\&t=628s

González, L. (4 de octubre de 2020). Informe de masacres en Colombia durante el 2020. Recuperado de: http://www.indepaz.org. co/informe-de-masacres-en-colombiadurante-el-2020/

Indepaz [@Indepaz] (4 de octubre de 2020). Ana Lucía Busbicús García, Comunidad indígena Awá Barbacoas, Nariño 03 de octubre de 2020, 223 líderes y defensores de derechos humanos asesinados durante el 2020, 82 indígenas asesinados en el 2020, \#PazParaLiderar [tuit]. Recuperado de: https://twitter.com/Indepaz/ status/1312920215391436800

Magendzo, A. (2005). Educación en Derechos Humanos, Un desafío y una misión irrenunciable para maestros. Bogotá, Colombia. Magisterio

Ministerio de Educación Nacional. (2009) Programa de Educación para el ejercicio de los Derechos Humanos. Eduderechos. Módulo 1: La educación para el ejercicio de los derechos humanos en la escuela: Un compromiso de todos

Ministerio de Educación Nacional. (2011) Orientaciones para la institucionalización de las Competencias Ciudadanas, Brújula. Programa de Competencias Ciudadanas. 
Ministerio de Educación Nacional. (2016) Derechos Básicos de Aprendizaje, Ciencias Sociales, Versión 1. Recuperado de; http://aprende. colombiaaprende.edu.co/sites/default/ files/naspublic/DBA_C.Sociales.pdf

Ministerio de Educación Nacional. (2018) Lineamientos de Formación de Educadores para la Ciudadanía Proyecto "Desarrollo e integración curricular de la Educación para la Ciudadanía Mundial - ECM.

Objetivos de Desarrollo Sostenible. (7 de octubre de 2020). 4. Educación de calidad. Recuperado de https://www.ods.gov.co/ es/objetivos/educacion-de-calidad

Oficina del Alto Comisionado para los Derechos Humanos de las Naciones Unidas (ACNUDH). (28/09/2020). ¿Qué son los derechos humanos? Recuperado de; https://www.ohchr.org/sp/ issues/pages/whatarehumanrights. a s p x\# : \% $7 \mathrm{E}: \mathrm{te} \times \mathrm{t}=\mathrm{L}$ os $\% 20$ derechos $\% 20$ hum anos $\% 20$ son $\% 20$ derechos, lengua $\% 2 \mathrm{C} \% 20$ o $\% 20$ cualquier $\% 20$ o tra $\% 20$ condici\%C3\%B3n.\&text=Estos $\% 20$ derechos $\% 20$ s o n $\% 20$ interrelacionados $\% 2$ C $\% 20$ interdependientes $\% 20 \mathrm{e} \% 20$ indivisibles

ONU: Asamblea General, Declaración Universal de Derechos Humanos, 10 diciembre 1948, 217 A (III), disponible en: https:// www.un.org/es/universal-declarationhuman-rights/

Pérez Luño, A. Derechos Humanos, Estado de Derechos y Constitución, 6a ed. Madrid. Tecnos

Presidencia de la República de Colombia. (25 de mayo de 2015) Por el cual se reglamenta la catedra de la paz
[Decreto 1038 de 2015]. Recuperado de: http://www.sipi.siteal.iipe.unesco. org/sites/default/files/sipi_normativa/ decreto_1038_de_2015_catedra_de_ la_paz_-colombia.pdf

Rodino, A. M. (2017). Educación en derechos humanos para una ciudadanía democrática e inclusiva: trabajar en la escuela y desde la Educación Física. Ensaio: Avaliação e Políticas Públicas em Educação, 20(74), 207227. https://doi.org/10.1590/s010440362012000100011

Rodino, A. M. (2016). Educación y derechos humanos: complementariedades y sinergias. Conferencia Magistral 20142015 Cátedra UNESCO de Educación para la Paz. Universidad de Puerto Rico. San Juan, Puerto Rico.

Russi Quiroga, A. (2011) Educación en Derechos Humanos, mirada al panorama colombiano. Revista investigación, desarrollo e innovación. Vol.2 [Nº.1] 8 $-2$

Vicepresidencia de la República de Colombia, Defensoría del Pueblo \& Ministerio de Educación Nacional. (2010), Plan Nacional de Educación en Derechos Humanos, contenido en documento PLANEDH. 